\title{
Respiratory infections and the autumn increase in asthma morbidity
}

\author{
R.E. Dales*, I. Schweitzer*, J.H. Toogood**, M. Drouin*, W. Yang*, \\ J. Dolovich+, J. Boulet*
}

Respiratory infections and the autumn increase in asthma morbidity. R.E. Dales, I. Schweitzer, J.H. Toogood, M. Drouin, W. Yang, J. Dolovich, J. Boulet. @ERS Journals Ltd 1996.

ABSTRACT: Unexplained autumn increases in hospital admissions for asthma have been reported in many countries, including the United States, Canada, England and Wales.

To investigate the role of infection, the association was tested between hospital admissions for asthma and respiratory infections among preschool children in Metropolitan Toronto, Canada during the period 1981 to 1989. The seasonal pattern in overall hospital utilization was assessed by admissions for nonrespiratory diseases. Time series analysis was used to remove potentially confounding temporal trends and the influence of correlated errors.

A fourfold increase in asthma admissions occurred between July and October unaccompanied by similar increases in nonrespiratory admissions. Admissions began increasing during the third week of August, peaked during the third week in September, and slowly decreased during November and December. After adjusting for serial correlation, trends, climate, ambient air pollution and aeroallergens, the seasonal pattern of respiratory infection explained $14 \%$ of the variance in asthma admissions.

Based on seasonal patterns, respiratory infection is the major identifiable risk factor for the large autumnal increase in asthma admissions.

Eur Respir J., 1996, 9, 72-77.

\author{
*University of Ottawa , **University of \\ Western Ontario, and +McMaster University, \\ Canada.
}

Correspondence: R.E. Dales, Dept of Medicine, Ottawa General Hospital, 501 Smyth Road, Ottawa, Ontario, Canada, K1H 8L6

Keywords: Air pollution

asthma

environment

fungi

infection

Received: January 121995

Accepted after revision September 201995

This work was supported by a grant from the Physicians' Services Incorporated foundation, Canada.
The increase in exacerbations of asthma occurring in the autumn was recognized by Hippocrates [1] and has since been reported in several countries. During the period 19651967, SAlvaggio et al. [2] observed that daily asthma admissions to the Charity Hospital in New Orleans were greatest from September until November. In New York, during 1969-1971, GoLDSTEIN [3] found that 50\% of the annual asthma admissions occurred between September and November. More recently, WEISS [4] reported on a US National sample of hospital discharges between 1982 and 1986. Fifty percent increases above the expected annual average were found from September until October for the 5-34 yrs age group. In England and Wales, Кнот et al. [5] reported a 50\% seasonal increase in asthma admissions (above the annual average) between 1975-1981. In Ontario, Canada, MAO et al. [6] demonstrated a 50\% increase (above the yearly average) in asthma admissions and a $60 \%$ increase in asthma mortality during September and October, for the period 1979-1986. In another Canadian study, BATES et al. [7] detected an approximate doubling of Emergency Department visits for asthma in Vancouver during late September, 1984-1986.

The aetiology of this phenomenon has remained elusive despite its large impact on population health. In 1970, SAlvagGio et al. [2] postulated that the seasonal outbreaks in New Orleans were due to an aeroallergen and in 1971 reported a temporal association with ambient spores resembling large basidiospores [8]. In a 1981 review of mould-induced asthma, SALVAGGIO and AuKrust [9] concluded that "a firmly established cause and effect relation has not been proved". GolDSTEIN [3], observing that most asthma "epidemics" in New Orleans and New York were preceded by cold fronts followed by high pressure systems, postulated that new air was carrying unidentified "asthmatogens". Other hypotheses have included viral infections and changes in indoor air quality associated with heating $[5,7]$.

The present aggregate risk study investigates the role of respiratory infections in the seasonal asthma peak using a combination of hospital admission and environmental data.

\section{Materials and methods}

\section{Reference population}

The reference population comprised approximately 400,000 preschool children of Metropolitan Toronto, Canada, which included the boroughs of York, North York, East York, Scarborough, Etobicoke, and City of Toronto. The unit of study was emergency and urgent 
hospital admissions for asthma among children less than 5 yrs of age. Hospital admission data for the province of Ontario, for the years 1981-1989, were provided by the Ontario Ministry of Health, Toronto, Canada. Data extracted were: age, date of birth, place of residence, date of admission, admission code (elective, urgent, emergency) and principal diagnosis coded according to International Classification of Disease (ICD)-9 [10]. Admissions were categorized into mutually exclusive groups by principal diagnosis: asthma (ICD 493), croup (ICD 464), acute bronchitis/bronchiolitis (ICD 466) and pneumonia (ICD 486). Respiratory infection was defined as croup, acute bronchitis/bronchiolitis and pneumonia.

A nonrespiratory group was chosen to define autumn changes in patient or hospital activities which may affect admission rates. For example, hospital bed closures or vacation period outside the city could cause seasonal changes in admissions. This group contained diseases not known to be associated or confused with infection or respiratory diseases and excluded accidents, suicides and other diseases which could have seasonal associations. Thus the nonrespiratory group consisted of diseases of the cerebrovasculature, oesophagus, appendix, intestine, gall bladder, biliary tree, pancreas, kidney and urinary tract (ICD 430-434, 530, 540-543, 560, 574-577, 584-586, 591-594, respectively).

\section{Meteorological data}

Daily meteorological data for Toronto during 1981-1989 was obtained from the Canadian Climate Centre, Downsview, Canada. It consisted of total precipitation, minimum relative humidity, mean windspeed, mean temperature, and mean barometric pressure.

\section{Air pollution data}

Pollution data for 1983-1988 were collected at the Breadalbane Street monitoring station in downtown Toronto and supplied by the Ontario Ministry of the Environment, Air Resources Branch. The maximum daily $1 \mathrm{~h}$ values for ozone, nitrogen dioxide and sulphur dioxide were used. $\mathrm{SO}_{2}$ was measured by a pulsed fluorescent $\mathrm{SO}_{2}$ monitor, whilst $\mathrm{NO}_{2}$ was measured by chemiluminescence [11]. Daily sulphate and nitrate levels in air were measured at the Air Resources Branch by ion chromatographic methods [12]. Daily total suspended particulates (TSP) were measured by the degree of light transmission through a paper tape running continuously behind a sampling inlet, which permitted passage of particles less than $10 \mu \mathrm{m}$ in diameter.

\section{Aerobiological data}

The analysis focused on the aeroallergens which predominate in the late summer and early autumn, since this was the time of the asthma peak. In Ontario, these allergens are ragweed and basidiospores [13-16]. The tree and grass pollen seasons end in June and July, respectively. Total spore counts, including Cladosporium and Alternaria, peak during the warmest period, July and
August, and decline through September (table 1).

For the period 1985-1989, ragweed counts were available from a Burkard Seven-Day Recording Volumetric Spore Trap (Burkard Manufacturing Co. Ltd) located approximately $100 \mathrm{ft}$ above the ground on the roof of McMaster University Medical Centre in Hamilton, which is approximately 25 miles southwest and upwind of Metropolitan Toronto. Hamilton trends should be applicable to Toronto, as evidenced by the similarity in ragweed counts between cities in Ontario hundreds of miles apart $[13,14,16]$.

For 1 year only (1989), Toronto ragweed data were available. The correlation with the Hamilton site was $\mathrm{r}=0.96$. The only available source of ambient spore concentrations which included basidiospores (mushroom spores) was Ottawa, Ontario, approximately $400 \mathrm{~km}$ east of Toronto. Applying these data to Toronto was probably justified because of the high correlation $(r=0.97)$ between asthma admissions between the two cities and because the correlation between basidiospores and asthma admissions in Ottawa $(r=-0.06)$ was similar to the correlation between these two variables in Toronto $(r=-0.05)$. Spores in Ottawa were collected between 1985 and 1991 using a rotorod. Counts were first performed on 15 randomly chosen fields magnified 20 times and repeated on 15 additional randomly chosen fields magnified 40 times. When counts were compared between each of the two rods of the rotorod, correlation coefficients were $\mathrm{r}=0.95$ at both magnifications [16].

\section{Analysis}

Simple regression analyses, which assume that successive data points are independent, are generally inappropriate for this type of data, where the same variable is measured repeatedly over time. Therefore, autoregressive integrated moving average (ARIMA) models were employed to derive unbiased statistical tests of the associations between asthma and air pollutants, aeroallergens and admissions for respiratory infections. To ensure that the onset, peak and decline in the autumn increase were included, the time period used for analysis was mid-July to the end of December. The frequency of admissions in each category was expressed as a weekly, rather than as a daily, total to smooth the data and to adjust for the day-of-the-week effect; admissions are higher at the beginning than at the end of the week. The hospital admission data were standardized by dividing each weekly average by the annual average for each corresponding year to account for any trends in population growth.

Differencing [17] was used to remove unwanted temporal trends in variables that could cause spurious associations. Autocorrelation in successive time series points, that is the dependency of a value on its preceding value, was identified using correlograms, which illustrate the degree of autocorrelation, and removed by an auto-regressive process $[18,19]$. The pattern of autocorrelations indicated that, for all series, the autoregressive process was of the order one or two and no moving average processes were present. Estimation and diagnosis of the identified 
Table 1. - Monthly averages of hospital admissions (0-4 yrs age group), meterological variables (1981-1989), aeroallergens (1985-1989) and air pollutants (1983-1988).

\begin{tabular}{|c|c|c|c|c|c|c|}
\hline & July & August & September & October & November & December \\
\hline \multicolumn{7}{|l|}{ Hospital admissions $n$} \\
\hline Âsthma & 1.9 & 1.7 & 4.1 & 5.1 & 5.5 & 4.2 \\
\hline Nonrespiratory diseases & 0.4 & 0.5 & 0.3 & 0.5 & 0.4 & 0.3 \\
\hline \multicolumn{7}{|l|}{ Meterological variables } \\
\hline Temperature ${ }^{\circ} \mathrm{C}$ & 21.2 & 19.7 & 15.4 & 8.6 & 3.1 & -3.1 \\
\hline Humidity* \% & 46.3 & 50.2 & 55.7 & 58.7 & 64.7 & 69.1 \\
\hline \multicolumn{7}{|l|}{ Aeroallergens $\mathbf{n} \cdot \mathrm{mm}^{-3}$} \\
\hline Ragweed grains & - & 40.1 & 50.3 & - & - & - \\
\hline Total spores & 218.1 & 210.6 & 147.7 & 39.1 & 5.2 & 1.0 \\
\hline Basidiospores & 82.5 & 137.7 & 96.3 & 10.6 & 0.5 & 0.0 \\
\hline \multicolumn{7}{|l|}{ Air pollutants } \\
\hline Sulphates $\mathrm{g} \cdot \mathrm{m}^{-3}$ & 10.6 & 11.7 & 9.9 & 8.7 & 8.0 & 8.2 \\
\hline Nitrogen dioxide ${ }^{\dagger} \mathrm{ppm}$ & 54.0 & 46.5 & 42.7 & 42.7 & 34.6 & 33.3 \\
\hline Sulphur dioxide ${ }^{\dagger}$ ppm & 12.4 & 19.7 & 16.3 & 18.4 & 17.6 & 24.2 \\
\hline Nitrates $\mathrm{g} \cdot \mathrm{m}^{-3}$ & 5.2 & 4.6 & 4.0 & 4.2 & 3.9 & 4.1 \\
\hline Ozone $^{\dagger} \mathrm{ppb}$ & 57.6 & 52.1 & 37.7 & 23.4 & 15.1 & 16.0 \\
\hline Particulates $\mu \mathrm{g} \cdot \mathrm{m}^{-3}$ & 72.1 & 66.4 & 57.7 & 54.9 & 46.2 & 47.3 \\
\hline
\end{tabular}

*: minimum relative humidity; ${ }^{\dagger}$ one hour daily maximum. series were repeated until an adequate model was identified which accounted only for uncorrelated error.

The resultant residuals for asthma and for respiratory infection were then correlated and tested for the statistical significance of their association. Multiple linear regression was then used to adjust for the influence of other environmental variables. The variance, explained by respiratory infection alone, was considered to be the difference in the $\mathrm{R}^{2}$ between a model containing meteorological, air pollution and aeroallergen data, and a model with these variables plus respiratory infection.

\section{Results}

For each of the years 1981 until 1989, a large autumnal increase in asthma admissions occurred, unaccompanied by a similar increase in admissions for nonrespiratory diseases (table 1 and fig. 1). A smaller peak occurred

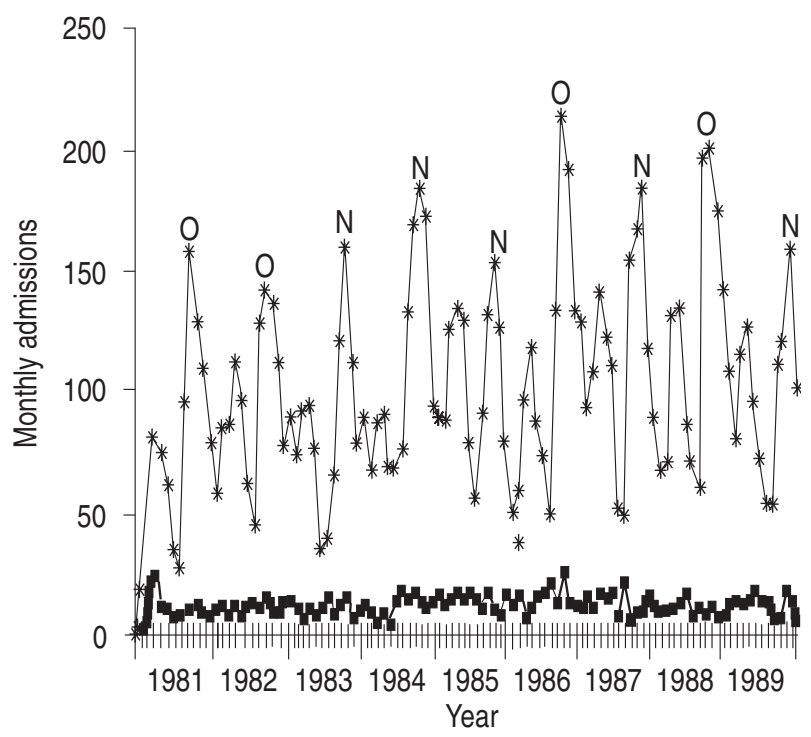

Fig. 1. - Monthly asthma and nonrespiratory admissions 1981-1989. The largest annual peaks in hospital admissions for asthma among Toronto residents occurred each year either in October or November 1981 to 1989 . The pattern of nonrespiratory admissions was dissimilar to that of asthma. O: October; N: November. $\longrightarrow \times$ : asthma;

reproducibly during the spring of each year. Averaged over the 9 yrs (fig. 2), the increase began during the third week in August (week 34), reached a maximum by the third week in September (week 39), and began to decline by the beginning of December (week 48). Admissions for croup (ICD 464) roughly paralleled the onset, peak and decline in admissions for asthma but the admission patterns were not superimposable, indicating a less than perfect correlation (fig. 2). Admissions for pneumonia and bronchitis/bronchiolitis also began rising at the same time as for asthma. However, these groups of respiratory infection rose more slowly and peaked approximately 10 weeks later than admissions for asthma (fig. 2).

The two late-season aeroallergens were ragweed and basidiospores (table 1 and fig. 3). Ragweed pollen concentrations increased whilst asthma admissions were lowest, and ragweed peaked and fell prior to the peak in

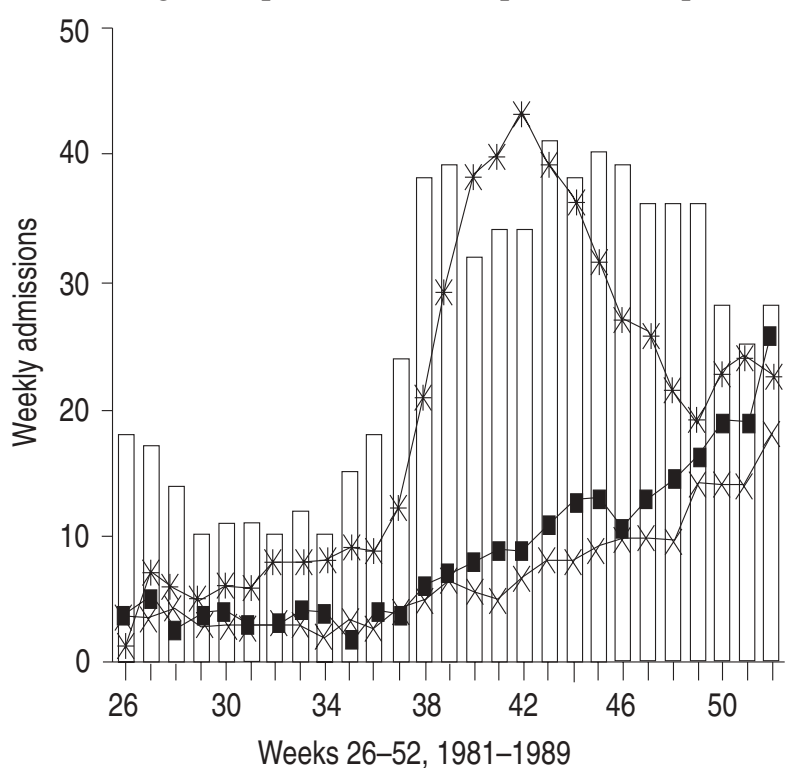

Fig. 2. - Weekly admissions for asthma, croup, bronchitis and pneumonia, weeks 26-52 averaged over 9 yrs. The trend in the weekly number of hospital admissions for asthma was similar to that of croup among children less than five years old during the period August to December, 1981 to 1989 . Admissions for bronchitis and pneumonia slowly increased during this period. $\square$ : asthma; $\rightarrow^{*}$ : croup; - : bronchitis; $\rightarrow$ : pneumonia. 


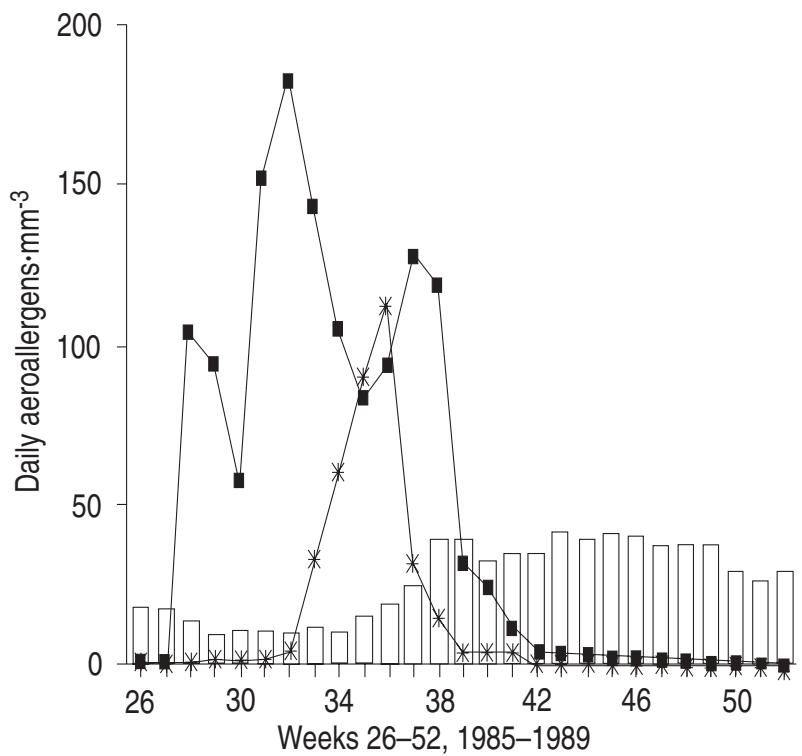

Fig. 3. - Mean daily concentrations of autumn aeroallergens, basidiospores and ragweed, averaged over the period 1985 to 1989 , declined during the period that asthma admissions increased. $\square$ : asthma; * : ragweed; - - : basidiospores.

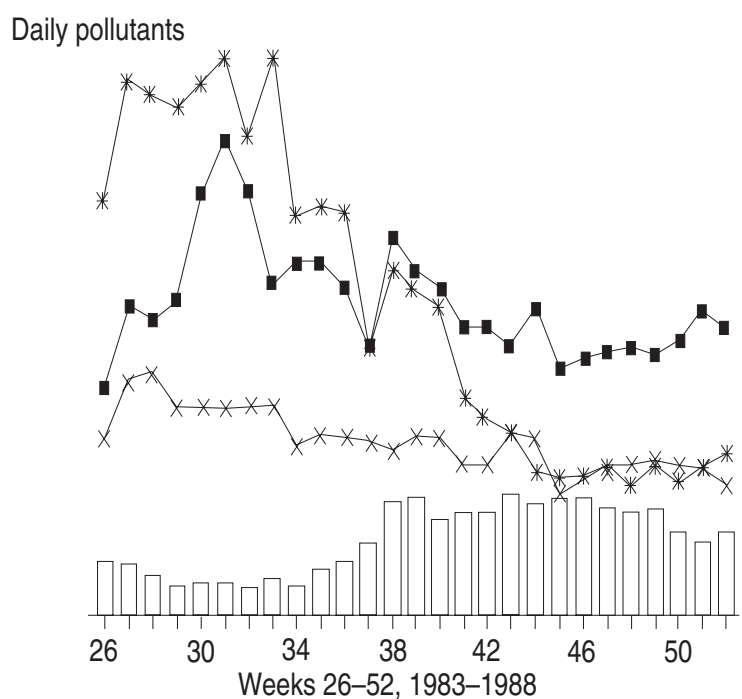

Fig. 4. - Mean daily concentrations of selected air pollutants, ozone, sulphates, and particles, averaged over the period 1983 to 1988, declined during the period that asthma admissions increased. For trends only, absolute values shown in table $1 . \square$ : asthma; $¥$ - : ozone; $\square-$ : sulphates; — : particles.

asthma. Similarly, basidiospore concentrations were highest in the summer months when asthma was at its lowest point, and spore concentrations declined just as asthma admissions began to peak.

Long-range transported air pollutants, ozone, sulphates and particles, also peaked during the summer months at the nadir of asthma admissions (fig. 4). Similarly, $\mathrm{SO}_{2}$, $\mathrm{NO}_{2}$, and nitrates (table 1) did not peak in the autumn.

One hundred and fifty weeks of hospital admissions were available for analysis, and complete data (admissions, climate, aeroallergens, ambient pollutants) were available for 90 weeks. Admissions for respiratory infections explained approximately $20 \%$ of the variance in asthma admissions (table 2). After removing serial autocorrelation
Table 2. - The association between weekly admissions for asthma and respiratory infections

\begin{tabular}{lccc}
\hline & \multicolumn{3}{c}{ Percentage of variance } \\
\cline { 2 - 4 } & $\begin{array}{c}\text { Unadjusted } \\
(\mathrm{n}=150)\end{array}$ & $\begin{array}{c}\text { Filtered } \\
(\mathrm{n}=150) \\
\%\end{array}$ & $\begin{array}{c}\text { Fully } \\
\text { adjusted } \\
(\mathrm{n}=90) \\
\%\end{array}$ \\
\hline Croup & $20^{*}$ & $5^{+}$ & $10^{\#}$ \\
$\begin{array}{l}\text { Bronchitis/bronchiolitis } \\
\text { Pneumonia }\end{array}$ & $18^{*}$ & 2 & 0 \\
$\begin{array}{l}\text { The above respiratory } \\
\text { infections combined }\end{array}$ & $22^{*}$ & $8^{+}$ & $4^{\#}$ \\
\hline
\end{tabular}

The percentages of the variance in asthma explained by infection are presented unadjusted (150 weeks of observation), then adjusted for serial autocorrelation and trending (filtered), and finally fully adjusted (90 weeks) for serial autocorrelation, trending and the climate, air pollution and aeroallergen data listed in table 1. *: $\mathrm{p}=0.0001 ;$ +: $\mathrm{p}<0.005 ;$;: $\mathrm{p}<0.01$.

and slow-moving trends in all variables, the relation to respiratory infection explained $14 \%$ of the variance in asthma $(\mathrm{p}<0.01)$ after adjusting for climate, ambient air pollution and aeroallergens. Thus, not only were admissions for infection correlated with asthma over the season, but week-to-week changes in infection also correlated with week-to-week changes in asthma admissions within the season.

\section{Discussion}

The threefold increase in hospital admissions for asthma in autumn was associated with increased admissions for respiratory infection but not with measured air pollutants or aeroallergens. This suggests that respiratory infection is the major identifiable risk factor for the dramatic rise in asthma morbidity during the autumn. This relationship is biologically plausible.

It is recognized that several types of viral infection can exacerbate asthma [20-23]. One of these, rhinovirus, is the most common cause of colds, and its frequency rises in August and peaks in September or October [21], a time trend similar to that observed for asthma admissions. The seasonal trend in croup is associated with that of parainfluenza, which is the virus most commonly isolated during acute episodes [24]. Other common viral isolates include respiratory syncytial virus and rhinovirus. Respiratory syncytial virus is also a cause of bronchiolitis and pneumonia.

AYRES [25] reported data from a general practice registry for the period 1976-1983 in the United Kingdom. During the autumn, attack rates of asthma coincided with acute bronchitis, which is an indicator of respiratory infection. Consistent with the study by Ayres [25], which did not adjust for secular trends, the unadjusted association with bronchitis in the present study was also statistically significant. This association, however, did not persist after adjustment, suggesting that either an unmeasured (confounding) variable created an artifactual relationship between asthma and bronchitis, or the present analysis minimized the estimate of effect. To minimize temporal confounding, the time-series analysis tested only the association between weekly changes in asthma 
admissions and weekly changes in infection admissions, not the association between the absolute number of admissions for asthma and bronchitis.

Increased asthma admissions could have resulted from changes in population, physician and hospital practices. However, the unchanging pattern of nonrespiratory admissions during the autumn did not support this hypothesis. Aeroallergens are known to cause acute asthmatic reactions within several minutes, to increase responsiveness to other nonspecific exposures and to have a "priming effect", whereby repeated exposures to an allergen cause a progressively greater reaction to smaller doses [26-29]. The asthma epidemics in late summer and early fall in New Orleans were associated with high concentrations of small spores but a causal relationship was never proved $[8,9]$. In the present study, however, the observed asthma peak occurred several weeks after the ragweed and basidiospore peaks and the asthma-infection association persisted after controlling for these factors. Other recognized aeroallergens have disappeared or are declining when asthma admissions begin to rise in late August. Tree pollens peak in April and May, and grass pollens in June $[13,14,16]$. The spores of Alternaria and Cladosporium are highest from June to early September [13-16]. In agreement with these findings, a recent study of Emergency Department visits for asthma in Finland [30] found no association with pollen measured from March to October.

Ambient air pollutants have been associated with exacerbations of asthma. During the peak period of ozone and sulphates in Ontario, between May and August, daily changes in air pollution may account for approximately $7 \%$ of asthma admissions [31]. Similar to the aeroallergen data, this study did not try to determine whether air pollutants contribute to asthma admissions in general because the focus of this study was the autumn peak and figure 4 demonstrates no major contribution of the measured pollutants to the phenomenon under study.

Finally, in support of the role of respiratory infection is the absence of other plausibly related but unmeasured factors which may have confounded the associations observed. Although the cool, damp autumn days have been considered risk factors for asthma, they may only be risk indicators [32]. GoLDSTEIN [3] reported that asthma epidemics in New Orleans were preceded by a cold front and then a high pressure system. Physiologically, it is difficult to attribute climatic changes per se to the autumn asthma peak. If low temperatures were the problem, winter should be the worst time (table 1). Similarly, although large temperature fluctuations exist in the autumn, people are exposed to much larger extremes during winter moving between the indoors and outdoors.

This study could not address changes in indoor air quality. Indoor moulds have the potential to cause illness [33] but little is known about the seasonal distribution in Ontario. MurRay et al. [34] reported that, among dust-mite sensitive individuals, asthma symptoms may be worse in the late autumn. The seasonal activation of forced air heating, by agitating and rendering dust airborne, may also aggravate asthma during autumn, but two studies found no association between forced air heating and asthma morbidity $[35,36]$.

Although we found a robust association between admissions for asthma and for respiratory infection, the temporal distributions did not perfectly coincide and only $14 \%$ of the variance in asthma admissions was explained. There are three possible explanations for this observation. Firstly, infection may be the predominant cause of the autumn epidemic but the proxies used for infection are not sensitive. The most common respiratory virus causing infection, rhinovirus [37], usually causes upper respiratory symptoms that do not require hospital admission. Secondly, the type of analysis used carefully controls for temporal biases in serial data at the cost of providing very conservative estimates of effect. The most extreme example of this was the correlation between asthma and bronchitis/bronchiolitis. Given that respiratory syncytial virus has been linked both to wheezing and bronchiolitis $[37,38]$, a true correlation between asthma and bronchitis/bronchiolitis would be expected but after accounting for potential confounding, the correlation fell from $r=0.4$ to $\mathrm{r}=0.0$. Thirdly, certain viruses are more likely than others to cause wheezing. These include rhino-virus, respiratory syncytial virus and parainfluenza [38]. The proxies used for these infections in the present study, bronchitis/bronchiolitis, pneumonia and croup are also proxies for other viruses and some nonviruses which may not be strongly associated with wheezing. Thus, the measured correlation is expected to be lower than if actual viral infection rates and identification were used. Despite these shortcomings, a clear association was found between respiratory infections and asthma, which persisted after extensive adjustment for potentially spurious associations.

Further testing of this hypothesis must await advances in the identification of the organisms that cause respiratory infection. Rhinovirus infection cannot be accurately assessed by serology and cultures are insensitive. Although currently expensive and not widely available, the polymerase chain reaction technique may prove to be useful in this respect [38]. The relation to infection is unproven and there may be unidentified trigger factors (other than infection, air pollutants and aerobiologicals) responsible for the seasonal pattern observed. However, it seems unnecessary to invoke other triggers until infections have been studied in more detail.

In summary, the present study of preschool children provides evidence that respiratory infection, probably viral, may cause the autumn increase in asthma admissions. Our results dispute the theories that changes in hospital practice (indicated by admissions for nonrespiratory diseases), ambient aeroallergens or air pollutants are responsible.

Acknowledgements: The authors thank J. Vila, Biostatistician, Ontario Ministry of Health for providing the hospital admission data, J. Anderson for providing pollen counts for London, Ontario, L. Coates for providing ragweed and spores data for Ottawa, Ontario, M. Webb, Atmospheric Environment Service, Environment Canada for providing the meteorological data, and the Ontario Ministry of the Environment, for providing the air pollution data. 


\section{References}

1. Adams F. In: The genuine works of Hippocrates. Baltimore; The Williams and Wilkins Co., 1939; pp. 299-300.

2. Salvaggio SJ, Hasselblad V, Seabury C, Heiderscheit LT New Orleans Asthma. II. Relationship of climatologic and seasonal factors to outbreak. J Allergy 1970; 45: 257-265.

3. Goldstein IF. Weather patterns and asthma epidemics in New York City and New Orleans, USA. Int J Biometeorol 1980; 24: 329-339.

4. Weiss KB. Seasonal trends in US asthma hospitalizations and mortality. J Am Med Assoc 1990; 263: 2323 2328

5. Khot A, Burn R, Evans N, Lenney C, Lenney W. Seasonal variation and time trends in childhood asthma in England and Wales 1975-1981. Br Med J 1984; 289: 235-237.

6. Mao Y, Semenciw R, Morrison H, Wigle DP. Seasonality and epidemics of asthma mortality and hospital admission rates, Ontario, 1979-1986. Can J Public Health 1990; 81: 226-228.

7. Bates DV, Baker-Anderson M, Sizto R. Asthma attack periodicity: a study of hospital emergency visits in Vancouver. Environ Res 1990; 51: 51-70.

8. Salvaggio J, Seabury J, Schoenhard TE. New Orleans Asthma. V. Relationship between charity hospital asthma admission rates, semiquantitative pollen and fungal spore counts, and total particulate aerometric sampling data. J Allergy Clin Immunol 1971; 48: 96.

9. Salvaggio J, Aukrust L. Postgraduate course presentations: mould-induced asthma. J Allergy Clin Immunol 1981; 68: 327-346.

10. World Health organization. International Classification of Diseases. 1975 Revision. Geneva, 1977.

11. Environment Ontario, Laboratory Services Branch. The determination of chloride, nitrate and sulphate on high volume filters by ion chromatography (anion HV-E3004A), 1990

12. Dobrin DJ, Potvin R. Air quality monitoring studies in the Subdury area, 1992. ISBN 07729 8724-6.

13. Chatterjee J, Hargreaves FE. Atmospheric pollen and fungal spores in Hamilton in 1972 estimated by the Hirst automatic volumetric spore trap. Can Med Assoc J 1974; 110: 659-663.

14. Coates LL, Crompton CW, Yang WH, Drouin MA. Comparative analysis of the pollen grains and mold spores of Ottawa 1985-1991. Clin Invest Med 1992; 15 (Suppl.): A7.

15. Li DW, Kendrick B. A year-round comparison of fungal spores in indoor and outdoor air. Mycologia 1995: 87: 190-195.

16. The pollen and spore report - 1994. A publication of the Canadian Society of Allergy and Clinical Immunology.

17. Norman RN, Streiner DL. Time Series Analysis. In: PDQ Statistics. Toronto, B.C., Dekker Inc., 1986; pp. 71-77.

18. SAS Institute Inc. SAS user's guide: statistics, version. 5th edn. Cary, NC, SAS Institute, Inc., 1985; pp. 171354.

19. Makridakis S, Wheelwright SC, McGee VE (eds). Forecasting methods and applications. 2nd edn. Toronto, John Wiley and Sons, 1983.

20. Gwaltney JM Jr. The common cold. In: Mandell GL, Douglas RG Jr, Bennett JE, eds. Principles and Practice of Infectious Diseases. 3rd edn. New York, Churchill Livingstone, 1990; pp. 45-49.

21. Levandowski RA. Rhinoviruses. In: Gorbach SL, Bartlett JG, Blacklow NR, eds. Infectious Diseases. Toronto, WB Saunders Co., 1992; pp. 1780-1787.

22. Kondo S, Abe K. The effects of influenza virus infection on FEV1 in asthmatic children. Chest 1991; 100: 1235-1238.

23. Busse W. The contribution of viral respiratory infections to the pathogenesis of airway hyperreactivity. Chest 1988; 93: 1076-1082.

24. Phelan PD, Olinsky A, Robertson CF, eds. In: Respiratory Illness in Children. Oxford, Blackwell Scientific Publications, 1994; p. 59.

25. Ayres J. Seasonal pattern of acute bronchitis in general practice in the United Kingdom 1976-1983. Thorax 1986; 41: 106-110.

26. Boulet L-P, Cartier A, Thomson NC, Roberts RS, Dolovich $\mathrm{J}$, Hargreave FE. Asthma and increases in nonallergic bronchial responsiveness from seasonal pollen exposure. J Allergy Clin Immunol 1983; 71: 399-406.

27. Brown HM. The relationship of aerobiological data to seasonal allergic symptoms: a review of 27 years' experience. Immunol Allergy Pract 1992; 14: 318-329.

28. Anto JM, Sunyer J, Rodriguez-Roisin R, Suarez-Cervera M, Vazquez L, and the Toxicoepidemiological Committee. Community outbreaks of asthma associated with inhalation of soybean dust. N Engl J Med 1989; 320: 1097-1102.

29. Platts-Mills TAE, Pollart SM, Chapman MD, Luczynska $\mathrm{CM}$. Role of allergens in asthma and airway hyperresponsiveness. In: Kaliner MA, Barnes PJ, Persson CGA, eds. Asthma: Its Pathology and Treatment. New York, Marcel Dekker Inc., 1991; pp. 595-631.

30. Rossi OVJ, Kinnula VL, Tienari J, Huhti E. Association of severe asthma attacks with weather, pollen and air pollutants. Thorax 1993; 48: 244-248.

31. Burnett RT, Dales RE, Raizenne ME, et al. Effects of low ambient levels of ozone and sulfates on the frequency of respiratory admissions to Ontario Hospitals. Environ Res 1994; 6S: 172-194.

32. Van Arsdel PP Jr. Clinical causes of asthma. In: Weiss ED, Segal MS, Stein M, eds. oBronchial Asthma: Mechanisms and Therapeutics. 2nd edn. Boston, Little, Brown and Co., 1985; pp. 303-309.

33. Flannigan B, McCabe EM, McGarry F. Allergenic and toxigenic microorganisms in houses. J Appl Bacteriol 1991; 70: 61S-73S (Symposium Suppl.).

34. Murray AB, Ferguson AC, Morrison B. The seasonal variation of allergic respiratory symptoms induced by house dust mites. Ann Allergy 1980; 45: 347-350.

35. Dekker C, Dales R, Bartlett S, Brunekreef B, Zwanenburg H. Childhood asthma and the indoor environment. Chest 1991; 100: 922-926.

36. Dales RE, Fyfe M, Schweitzer I. Does forced air heating exacerbate asthma? J Allergy Clin Immunol 1992; 90: 803-807.

37. Pattemore PK, Johnston SL, Bardin PG. Viruses as precipitants of asthma symptoms. I. Epidemiology. Clin Exp Allergy 1992; 22: 325-336.

38. Johnston SL, Bardin PG, Pattemore PK. Viruses as precipitants of asthma symptoms. III. Rhinoviruses: molecular biology and prospects for future intervention. Clin Exp Allergy 1993; 23: 237-246. 